\title{
A Comparative Study of Topical Azailic Acid Cream 20\% and Active Lotion Containing Triethyl Citrate and Ethyl Linoleate in the Treatment of Mild to Moderate Acne Vulgaris
}

\author{
Hayder R. Al-Hamamy ${ }^{*}$, Adil A. Noaimi ${ }^{2,3}$, Ihsan A. Al-Turfy², Adil Ibrahim Rajab ${ }^{4}$ \\ ${ }^{1}$ Scientific Council of Dermatology and Venereology-Iraqi Board for Medical Specializations, Baghdad, Iraq \\ ${ }^{2}$ Department of Dermatology, College of Medicine, University of Baghdad, Baghdad, Iraq \\ ${ }^{3}$ Arab Board for Dermatology and Venereology, Baghdad Teaching Hospital, Medical City, Baghdad, Iraq \\ ${ }^{4}$ Department of Dermatology, Baghdad Teaching Hospital, Baghdad, Iraq \\ Email: ${ }^{*}$ hayder317@gmail.com, adilnoaimi@yahoo.com, dr ihssanalturfi@yahoo.com, \\ rajabadil729@yahoo.com
}

Received 24 June 2015; accepted 7 September 2015; published 10 September 2015

Copyright (C) 2015 by authors and Scientific Research Publishing Inc.

This work is licensed under the Creative Commons Attribution International License (CC BY). http://creativecommons.org/licenses/by/4.0/

(c) (i) Open Access

\section{Abstract}

Background: Acne vulgaris is a common disorder affecting $79 \%-95 \%$ of the adolescent population. The choice of treatment depends on the severity, patients with mild to moderate acne should receive topical therapy such as azelaic acid. Rising antibiotic drug resistance consequent to the widespread use of topical antibiotics is causing concern and effective non-antibiotic treatments are needed. Objective: To compare the efficacy and side effects of topical azelaic acid cream $20 \%$ versus active lotion containing triethyl citrate and ethyl linoleate (TCEL) in treatment of mild to moderate acne vulgaris. Patients and Methods: This single, blinded, comparative, therapeutic study was done in the Department of Dermatology-Baghdad Teaching Hospital, Baghdad, Iraq; from May 2013-July 2014. Scoring of acne was carried out and the patients were examined every 2 weeks for 10 weeks of treatment. One month after stopping drugs, patients were evaluated for drug complications and disease recurrence. Sixty patients fulfilling enrollment criteria were included in this study. Patients were divided into 2 groups: Group $A$ (30 patients) treated twice daily with TCEL lotion and Group B (30 patients) treated twice daily with topical azelaic acid cream $20 \%$. Results: Both topical TCEL lotion and azelaic acid cream were statistically an effective therapy for treatment of mild to moderate acne vulgaris. TCEL lotion was more effective and act earlier than

\footnotetext{
*Corresponding author.
}

How to cite this paper: Al-Hamamy, H.R., et al. (2015) A Comparative Study of Topical Azailic Acid Cream 20\% and Active Lotion Containing Triethyl Citrate and Ethyl Linoleate in the Treatment of Mild to Moderate Acne Vulgaris. Journal of Cosmetics, Dermatological Sciences and Applications, 5, 223-230. http://dx.doi.org/10.4236/jcdsa.2015.53027 
azelaic acid cream starting from 4 weeks of therapy till the end of treatment (after 10 weeks) and even after 4 weeks after stopping the treatment (P-value $<0.04)$. No systemic side effect for both groups was noted while the following side effects were reported; burning, pruritus and erythema, all these side effects disappeared after 8 weeks from starting treatment. After one month of follow up there was no significant relapse in both groups. Conclusion: The TCEL is non-antibiotic based, it had quicker onset of action and observable improvement of both inflammatory and non-inflammatory acne lesions. Its use would reduce the risk of antibiotic resistance developing within the skin flora.

\section{Keywords}

Acne Vulgaris, Inflammatory, Aknicare, Azelaic Acid

\section{Introduction}

Acne vulgaris is the most common chronic inflammatory skin disease. It affects mainly young people at the sensitive period of puberty and can have an adverse effect on their psychological development, which may lead to social phobias, withdrawal from society and clinical depression [1]-[3].

Current treatments for acne include topical and oral antibiotics, topical antimicrobials and topical and oral retinoids. All acne treatments have potential side-effects, some of which may be severe. Topical and oral antibiotics generally need to be used for several months to achieve a response, which leads to major problems with patient compliance. In addition to possible side-effects, long-term exposure to antibiotics has exerted enormous selective pressure on the bacterial skin flora of patients with acne, with the emergence of antibiotic-resistant propioni bacteria [4]-[6].

This has emphasized the need to develop new therapeutic options for the treatment of acne which are preferably non-antibiotic. Therefore, this study was arranged to investigate the efficacy and tolerability of a topical lotion composed of triethyl citrate and ethyl linoleate (TCEL lotion) as the active agents in the treatment of mild to moderate acne vulgaris.

\section{Patients and Methods}

This single, blinded, comparative, therapeutic study was carried out at the Department of Dermatology and Venereology-Baghdad Teaching Hospital, Baghdad, Iraq from May 2013-July 2014. Sixty patients were included in this study.

Full history was taken from each patient including: age, gender, duration of disease and previous treatment. Physical examination was done to evaluate the severity of acne.

Inclusion criteria were mild to moderate acne vulgaris. Exclusion criteria were severe and nodulocystic acne, coexistence of any other dermatoses involving the face and allergy to medications, plus patients who had used any topical and systemic treatments in the previous 2 months, pregnant and lactating women.

Acne was scored according to Global Acne Grading System (GAGS) [7].

Formal consent was taken from each patient before starting the trial of treatment, after full explanation for the nature of the disease, course of treatment, prognosis and complications, the target of the present work regarding the drug, its efficacy, side effects, the method and duration of treatment and follow up. Ethical approval was confirmed from Scientific Council of Dermatology and Venereology Iraqi Board for Medical Specializations.

Patients with mild to moderate acne vulgaris were divided into two groups (Figure 1, Figure 2):

Group A: Patients were treated with TCEL (Aknicare) lotion ${ }^{\circledR}$ (Active lotion containing triethyl citrate and ethyl linoleate) Produced by: General Topics s.r.l, Salo’ Italy. In this group 30 patients were instructed to apply Aknicare lotion twice daily for 10 weeks. Clinical evaluation was done every 2 weeks till the end of the $10^{\text {th }}$ week. Then patients were asked to stop the use of medication to be re-evaluated again after one month without any treatment to show any relapse. The assessment was carried out by (GAGS).

Group B: Patients treated with 20\% Azelaic acid cream [(AZELEC) ${ }^{\mathrm{R}}$ Produced by: Domina Pharmaceuticals Company, Damascus, Syria, 20\% cream]. In this group 30 patients were treated in the same manner as in Group 

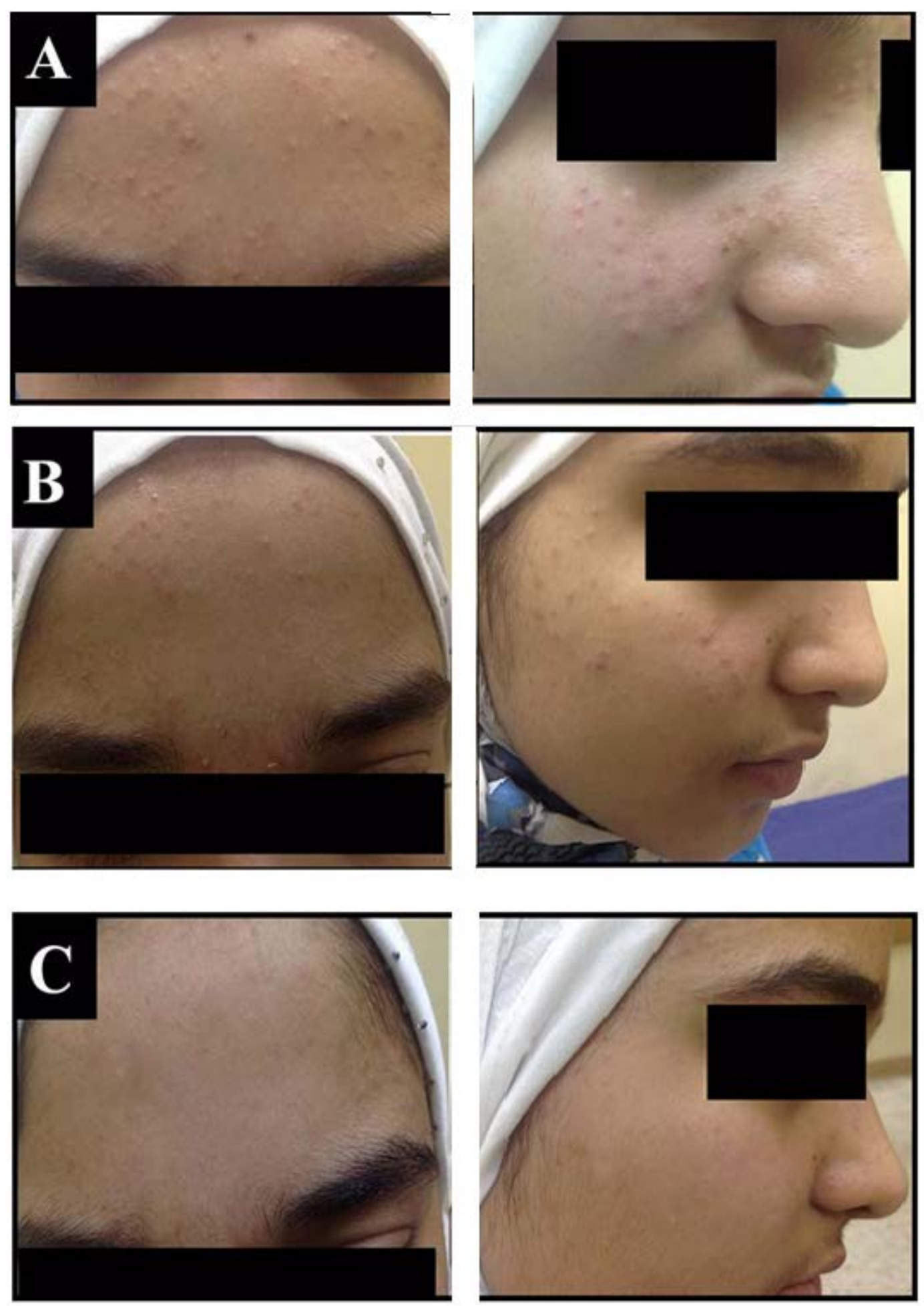

Figure 1. Seventeen years old female with moderate acne vulgaris (A) Before treatment; (B) after 4 weeks and (C) 10 weeks after treatment with topical TCEL lotion.

A patients. Any local or systemic side effects were recorded at each visit for both groups.

Quality of life before and at the end of therapy was measured using the Cardiff Acne Disability Index (CADI) [4]. Color photographs for each patient were obtained by using Sony-digital, high sensitivity, 16.1 megapixel 

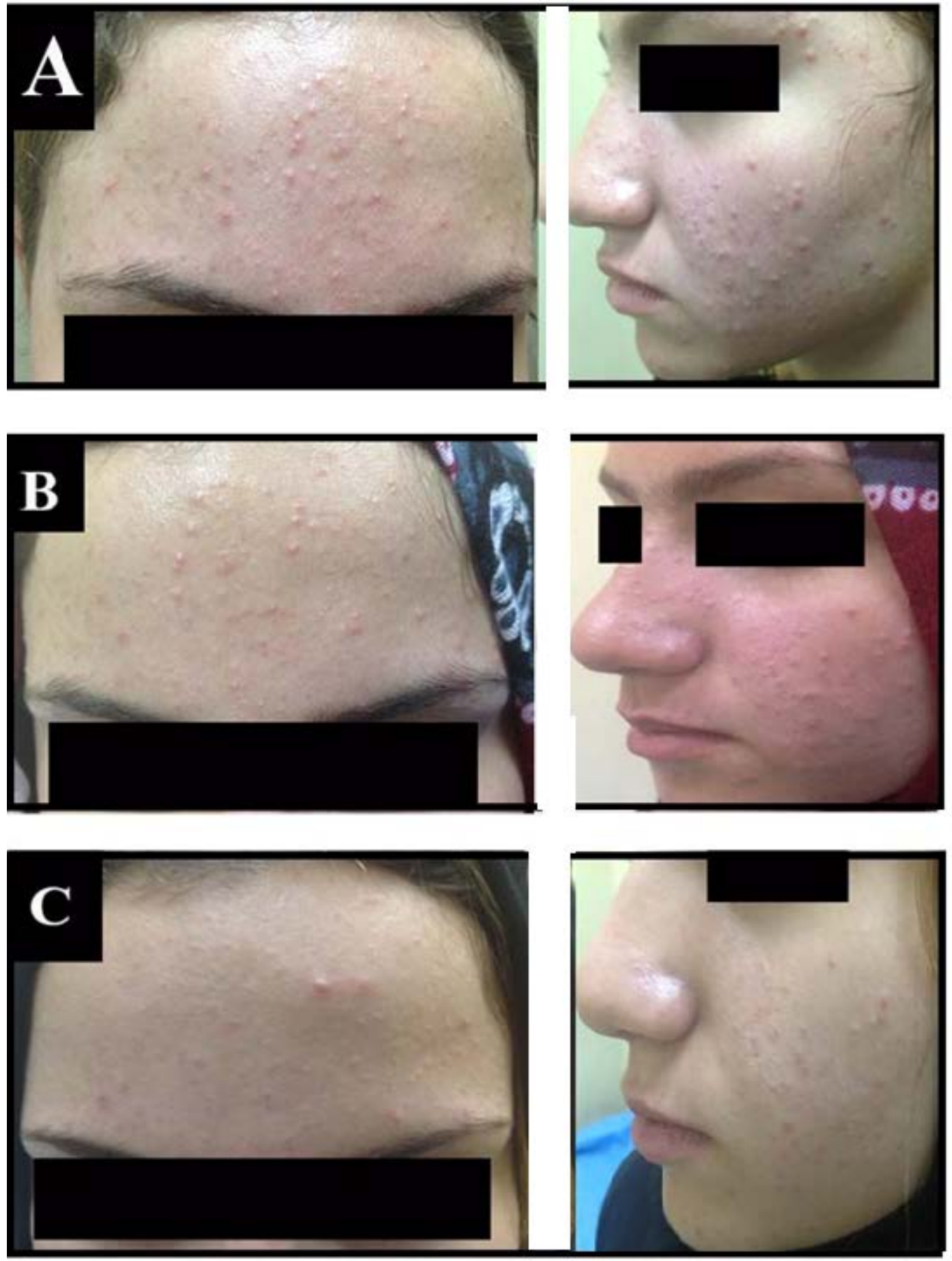

Figure 2. Twenty one years old female with moderate acne (A) Before treatment; (B) after 4 weeks and (C) 10 weeks after treatment with topical Azeliac acid cream 20\%.

camera with fixed illumination and distance and the same place.

Statistical analysis of data was carried out using the statistical package of SPSS-20 (Statistical Packages for Social Sciences-version 20). Data were presented in simple measures of frequency, percentage, mean and standard deviation. Comparison between groups was done by using independent sample t-test. Comparison before and after treatment in each group was done by using paired t-test, comparison of reduction rate of the lesions in 
both groups was done by using chi-square, and P-value $<0.05$ was considered as the level of significance.

\section{Results}

\section{- Demographic data:}

Patients in Group A, their mean age \pm SD was $20.33 \pm 3.85$ years, 21 were females and 9 were males with female to male ratio 2.3:1; Group B, their mean age \pm SD was $21.53 \pm 3.72$ years, 19 were females and 11 were female to male ratio 1.7:1.

The mean \pm SD of duration of acne in patients within Group $A$ was $11.1 \pm 5.58$ months, and the mean \pm SD for those in Group B was $11.50 \pm 5.24$ months. Both groups were statistically matched regarding age, gender and duration of the disease.

\section{- GAG Score}

In Group A (TCEL lotion), the GAG score diminished after 2 weeks of treatment from $24.03 \pm 5.07$ to 22.10 \pm 5.28 but this reduction was not statistically significant (P-value 0.15 ). At the $4^{\text {th }}$ week the GAG score was $19.53 \pm 5.35$ which was statistically significant when compared to baseline (P-value 0.04$)$. The GAG score continued to decrease till it became $18.23 \pm 6.03$ at $6^{\text {th }}$ week, $17.47 \pm 6.73$ at $8^{\text {th }}$ week and $16.00 \pm 6.13$ at $10^{\text {th }}$ week (P-value 0.016, 0.001, 0.0001 respectively).

In Group B (Azelaic acid cream), the GAG score diminished after 2 weeks of treatment from $24.60 \pm 5.16$ to $23.33 \pm 5.08$ but this reduction was not statistically significant (P-value 0.36 ). At the $4^{\text {th }}$ week the GAG score was $20.47 \pm 5.32$ which was statistically not significant when compared to baseline (P-value 0.056 ). The GAG score continued to decrease till it became $18.90 \pm 5.55$ at $6^{\text {th }}$ week, $17.83 \pm 6.35$ at $8^{\text {th }}$ week and $15.37 \pm 6.16$ at $10^{\text {th }}$ week and in all these 3 visits were statistically significant when compared to baseline (P-value $0.032,0.001$, 0.0001 respectively) (Table 1 ).

\section{- Percent reduction:}

The percent reduction rate of GAG score from baseline visit up to 10 weeks of treatment for Group A were 33.4\%, Group B were $27.5 \%$ (Table 2).

\section{- Patient satisfaction:}

Subjective improvement of acne was measured by using Cardiff Acne Disability Index (CADI); quality of life of patients in all groups showed less impairment at end of treatment in comparison with that at the beginning of therapy (P-value $<0.014$ for Group A, 0.023 for Group B. When comparing both groups, patients treated with TCEL lotion had lower CADI than azelaic acid cream but both were statistically significant (Table 3).

Table 1. Global Acne Grading system for patients in Group A (TCEL lotion) and Group B (Azelaic acid) at each visit (2 weeks interval).

\begin{tabular}{|c|c|c|}
\hline \multirow{2}{*}{ Visits } & \multicolumn{2}{|c|}{ GAG Score (Mean \pm SD) } \\
\hline & Group A & Group B \\
\hline Baseline & $24.03 \pm 5.07$ & $24.60 \pm 5.16$ \\
\hline \multirow{2}{*}{ After 2 weeks } & $22.10 \pm 5.28$ & $23.33 \pm 5.08$ \\
\hline & ${ }^{*} \mathrm{P}=0.15$ & ${ }^{*} \mathrm{P}=0.36$ \\
\hline \multirow{2}{*}{ After 4 weeks } & $19.53 \pm 5.35$ & $20.47 \pm 5.32$ \\
\hline & ${ }^{*} \mathbf{P}=\mathbf{0 . 0 4}$ & ${ }^{*} \mathrm{P}=0.056$ \\
\hline \multirow{2}{*}{ After 6 weeks } & $18.23 \pm 6.03$ & $18.90 \pm 5.55$ \\
\hline & ${ }^{*} \mathbf{P}=\mathbf{0 . 0 1 6}$ & ${ }^{*} \mathbf{P}=\mathbf{0 . 0 3 2}$ \\
\hline \multirow{2}{*}{ After 8 weeks } & $17.47 \pm 6.73$ & $17.83 \pm 6.35$ \\
\hline & ${ }^{*} \mathbf{P}=\mathbf{0 . 0 0 1}$ & ${ }^{*} \mathbf{P}=\mathbf{0 . 0 0 1}$ \\
\hline \multirow{2}{*}{ After 10 weeks } & $16.00 \pm 6.13$ & $15.37 \pm 6.16$ \\
\hline & ${ }^{*} \mathbf{P}=0.0001$ & ${ }^{*} \mathbf{P}=0.0001$ \\
\hline
\end{tabular}

\footnotetext{
*Statistically different from the $1^{\text {st }}$ visit within the same group (paired $t$ test).
} 
Table 2. Showing percent reduction rate for Group A (TCEL lotion) and Group B (Azelaic acid cream) at each visit (2 weeks interval).

\begin{tabular}{|c|c|c|}
\hline Visits & Group A & Group B \\
\hline Baseline & $\mathbf{0}$ & $\mathbf{0}$ \\
\hline After 2 weeks & $8 \%$ & $5.2 \%$ \\
\hline After 4 weeks & $18.7 \%$ & $16.8 \%$ \\
\hline After 6 weeks & $24.1 \%$ & $23.8 \%$ \\
\hline After 8 weeks & $27.3 \%$ & $27.5 \%$ \\
\hline After 10 weeks & $33.4 \%$ & $27.5 \%$ \\
\hline
\end{tabular}

* Percent Reduction $=(\mathbf{X}-\mathbf{Y}) / \mathbf{X} * 100, \mathbf{X}$ is an initial value, $\mathbf{Y}$ is a final value.

Table 3. The Cardiff Acne Disability Index for Group A (TCEL lotion) and Group B (Azelaic acid cream) before and at the end of treatment.

\begin{tabular}{|c|c|c|c|c|c|c|}
\hline \multirow{2}{*}{\multicolumn{2}{|c|}{ Cardiff Acne Disability Index }} & \multicolumn{2}{|c|}{ CADI Pre-treatment } & \multicolumn{2}{|c|}{ CADI Post-treatment } & \multirow{2}{*}{${ }^{*} \mathbf{P}$ value } \\
\hline & & $\mathrm{N}$ & $\%$ & $\mathrm{~N}$ & $\%$ & \\
\hline \multirow{3}{*}{$\begin{array}{c}\text { Aknicare } \\
\text { (TCEL lotion) }\end{array}$} & Mild impairment & $\mathbf{0}$ & $0.0 \%$ & 12 & $40.0 \%$ & \multirow{3}{*}{0.014} \\
\hline & Moderate impairment & 15 & $50.0 \%$ & 18 & $60.0 \%$ & \\
\hline & Severe impairment & 15 & $50.0 \%$ & $\mathbf{0}$ & $0.0 \%$ & \\
\hline \multirow{3}{*}{ Azelaic acid cream } & Mild impairment & $\mathbf{0}$ & $0.0 \%$ & 12 & $40.0 \%$ & \multirow{3}{*}{0.023} \\
\hline & Moderate impairment & 14 & $46.7 \%$ & 15 & $50.0 \%$ & \\
\hline & Severe impairment & 16 & $53.3 \%$ & 3 & $10.0 \%$ & \\
\hline
\end{tabular}

*Using Mann-Whitney Test for ordinal data.

\section{- Relapse rate:}

After one month of follow up, there was no significant relapse in Group A the CADI score was $16.00 \pm 6.13$ at the end of the 10 weeks of treatment and became $16.27 \pm 5.84$ four weeks following stopping treatment. In Group $B$ the CADI score was $15.37 \pm 6.16$ and became $15.47 \pm 6$.03.In both groups they did not increased significantly (P-value $=0.43$ in Group A, and 0.91 in Group B).

\section{- Side effects:}

The assessment of local side effects for Group A showed burning in 10 (33.3\%) patients, flare-up in 2 (6\%), dry skin in 9 (30\%), pruritus in 12 (40\%) and erythema in 6 (20\%) patient. All these symptoms disappeared after 8 weeks from starting treatment. The assessment of local side effects for Group B showed burning in 21 (70\%) of patients, erythema 18 (60\%), scaling 13 (43.3\%), flare-up in 2 (6\%), dry skin 20 (66.7\%) and pruritus 8 (26.7\%). All these symptoms disappeared after 8 weeks from starting treatment.

\section{Discussion}

Acne vulgaris is a common skin disease, affecting about $70 \%-80 \%$ of adolescents and young adults. It is a multifactorial disease of the pilosebaceous unit. The influence of androgens at the onset of adolescence leads to an enlargement of the sebaceous gland and a rise in sebum production. Additional increased proliferation and altered differentiation of the follicular epithelium eventually blocks the pilosebaceous duct, leading to development of the micro-comedones as the primary acne lesion. Concomitantly and subsequently, colonization with Propioni bacterium acnes increases, followed by induction of inflammatory reactions from bacteria, ductal corneocytes, and sebaceous pro-inflammatory agents [1]-[3]. Topical antibiotics are the main stay for mild to moderate inflammatory acne vulgaris [6].

This study demonstrates that this new lotion containing triethyl citrate and ethyl linoleate (TCEL lotion) (Ak- 
nicare) is an effective and well-tolerated topical agent in the treatment of mild to moderate acne vulgaris. The use of lotion twice daily for 10 weeks was associated with significant improvement in acne severity.

In the present study, both TCEL lotion cream and azelaic acid cream were shown to be effective in the treatment of mild to moderate acne vulgaris with significant improvement in GAG score after 6 weeks of treatment, while Aknicare acts quicker and was more effective in reduction of GAG score after 4 weeks of therapy.

No relapse was recorded in patients treated with TCEL lotion, and azelaic acid cream one month after stopping the treatment.

These results are comparable to other studies. As Charakida A et al. showed that TCEL lotion had significant reduction of inflammatory acne lesions within 4 weeks of treatment [8]. Akamatsu $\mathrm{H}$ et al. also showed significant reduction in inflammatory lesion count within the same period [9].

Elewski et al. [10] and Nazzaro-Porro $\mathrm{M}$ et al. [11] found that azelaic acid 15\% provided a significant reduction in the mean inflammatory lesion count. In the study of Thiboutot et al. [12], the mean reductions of inflammatory lesions in the azelaic acid $15 \%$ gel treated patients were $58 \%$ at the end of therapy, but the present study showed $36.4 \%$ decrement in GAG score and this difference may be due to different acne scoring in these studies.

The combination of ethyl linoleate and triethyl citrate can reduce the hyperkeratinization of the pilosebaceous duct, the bacterial colonization of the infundibulum by Propioni bacterium acnes and seborrhea, targeting the different steps in the pathogenesis of acne [13]-[15].

The exact mechanism of action in the treatment of acne is not yet known. The antimicrobial, anti-keratinization, and anti-inflammatory effects have been implicated. The antimicrobial action may be related to inhibition of microbial cellular protein synthesis. Azelaic acid is bactericidal against Propioni bacterium acnes, Staphylococcus epidermidis and possesses bacteriostatic properties against many other aerobic microorganisms [11] [12]. Effects of azelaic acid on neutrophils function have been studied by Akamatsu et al. [9] in 1991, and its ability to inhibit of the production of reactive oxygen species have been shown which may contribute the anti-inflammatory effects of azelaic acid. It has been reported that azelaic acid treatment achieved a reduction in the thickness of the stratum corneum, a reduction in the number and size of keratohyalin granules, and a reduction in the amount and distribution of filaggrin in epidermal layers [16].

Local side effects were more common in Azelaic acid. In spite of these side effects, both drugs were tolerable and no patient stopped treatment because of side effects.

The limitations of this study include small sample size and short duration of therapy.

\section{Conclusion}

In conclusion, the TCEL is non-antibiotic based; it had quicker onset of action and observable improvement of both inflammatory and non-inflammatory acne lesions. Its use would reduce the risk of antibiotic resistance developing within the skin flora.

\section{Disclosure}

This study is an independent study and not funded by any drug companies.

\section{References}

[1] Simpson, N.B. and Cunliffe, W.J. (2004) Disorders of the Sebaceous Glands. In: Burns, T., Breathnach, S., Cox, N., Griffiths, C., Eds., Rook’s Text Book of Dermatology, 7th Edition, Blackwell Science, 43, 1-7. http://dx.doi.org/10.1002/9780470750520.ch43

[2] Habif, T.P. (2010) Acne and Related Disorder. Clinical Dermatology: A Color Guide to Diagnosis and Therapy, 5th Edition, Edinburgh, 7, 217-247.

[3] Dreno, B. and Poli, F. (2003) Epidemiology of Acne. Dermatology, 206, 7-10. http://dx.doi.org/10.1159/000067817

[4] Sharquie, K.E., Gumar, A. and Al-Kodsi, Z. (1991) Acne Vulgaris Epidemiology and Grading. Saudi Medical Journal, 12, 44-47.

[5] Kurokawa, I., Danby, F.W., Ju, Q., Wang, X., Xiang, L.F., Xia, L., Chen, W., Nagy, I., Picardo, M., Suh, D.H., Ganceviciene, R., Schagen, S., Tsatsou, F. and Zouboulis, C.C. (2009) New Developments in Our Understanding of Acne Pathogenesis and Treatment. Experimental Dermatology, 18, 821-832. 
http://dx.doi.org/10.1111/j.1600-0625.2009.00890.x

[6] Katsamba, A. and Dessinioti, C. (2008) New and Emerging Treatments in Dermatology: Acne. Dermatology and Therapy, 21, 86-95. http://dx.doi.org/10.1111/j.1529-8019.2008.00175.x

[7] Doshi, A., Zaheer, A. and Stiller, M.J. (1997) A Comparison of Current Acne Grading Systems and Proposal of a Novel System. International Journal of Dermatology, 36, 416-418. http://dx.doi.org/10.1046/j.1365-4362.1997.00099.x

[8] Charakida, A., Charakida, M. and Chu, A.C. (2007) Double-Blind, Randomized, Placebo-Controlled Study of a Lotion Containing Triethyl Citrate and Ethyl Linoleate in the Treatment of Acne Vulgaris. British Journal of Dermatology, 157, 569-574. http://dx.doi.org/10.1111/j.1365-2133.2007.08083.x

[9] Akamatsu, H., Komura, J., Miyachi, Y., et al. (1990) Suppressive Effects of Linoleic Acid on Neutrophil Oxygen Metabolism and Phagocytosis. Journal of Investigative Dermatology, 95, 271-274. http://dx.doi.org/10.1111/1523-1747.ep12484890

[10] Elewski, B.E., Fleischer Jr., A.B. and Pariser, D.M. (2003) A Comparison of 15\% Azelaic Acid Gel and 0.75\% Metronidazole Gel in the Topical Treatment of Papulopustular Rosacea: Results of a Randomized Trial. Archives of Dermatology, 139, 1444-1450. http://dx.doi.org/10.1001/archderm.139.11.1444

[11] Nazzaro-Porro, M., Passi, S., Picardo, M., Breathnach, A., Clayton, R. and Zina, G. (1983) Beneficial Effect of 15\% Azelaic Acid Cream on Acne Vulgaris. British Journal of Dermatology, 109, 45-48. http://dx.doi.org/10.1111/j.1365-2133.1983.tb03990.x

[12] Thiboutot, D., Thieroff-Ekerdt, R. and Graupe, K. (2003) Efficacy and Safety of Azelaic Acid (15\%) Gel as a New Treatment for Papulopustular Rosacea: Results from Two Vehicle-Controlled, Randomized Phase III Studies. Journal of the American Academy of Dermatology, 48, 836-845. http://dx.doi.org/10.1067/mjd.2003.308

[13] Namazi, M.R. (2004) Further Insight into the Patho-Mechanism of Acne by Considering the 5-Alpha-Reductase Inhibitory Effect of Linoleic Acid. International Journal of Dermatology, 43, 701. http://dx.doi.org/10.1111/j.1365-4632.2004.02200.x

[14] Charakida, A., Charakida, M. and Chu, A.C. (2007) Double-Blind, Randomized, Placebo-Controlled Study of a Lotion Containing Triethyl Citrate and Ethyl Linoleate in the Treatment of Acne Vulgaris. British Journal of Dermatology, 157, 569-574. http://dx.doi.org/10.1111/j.1365-2133.2007.08083.X

[15] Park, S.Y., Seetharaman, R., Ko, M.J., Kim do, Y., Kim, T.H., Yoon, M.K., Kwak, J.H., Lee, S.J., Bae, Y.S. and Choi, Y.W. (2014) Ethyl Linoleate from Garlic Attenuates Lipopolysaccharide-Induced Pro-Inflammatory Cytokine Production by Inducing Heme Oxygenase-1 in RAW264.7 Cells. International Immunopharmacology, 19, 253-261. http://dx.doi.org/10.1016/j.intimp.2014.01.017

[16] Fitton, A. and Goa, K.L. (1991) Azelaic Acid: A Review of Its Pharmacological Properties and Therapeutic Efficacy in Acne and Hyperpigmentary Skin Disorders. Drugs, 41, 780-798. http://dx.doi.org/10.2165/00003495-199141050-00007 